POLIGRAFÍAS. REVISTA DE TEORÍA LITERARIA Y LITERATURA COMPARADA.NÚMERO 2.OTOÑO 2012 OUNAM TODOS LOS DERECHOS RESERVADOS

https://doi.org/10.22201/ffyl.poligrafiasnuevaepoca.2012.2.1666

\title{
Poe entre las sombras: una poética del silencio ${ }^{1}$
}

\author{
Adrián Muñoz \\ Facultad de Filosofía y Letras, UNAM
}

Una cosa, hasta no ser toda, es ruido, y toda, es silencio.

Antonio Porchia

De acuerdo con Arthur Brown (1996: 449), para poder apreciar seriamente la obra de Poe es menester reconocer la palpable realidad del terror que, como lectores, experimentamos al confrontar la evidencia de una "muerte imperecedera". Ahora bien: el terror y la muerte, en Poe, trascienden la mera narrativa del homicidio, de la pérdida de un ser querido o de seres fallecidos que retornan para cobrar venganza. En algunos textos, Poe vincula el sentimiento de terror y la muerte con experiencias que suponen un contacto con una realidad ulterior. Estas experiencias bien pueden catalogarse como numinosas y, como tales, trastocan el papel del lenguaje. Lo numinoso supone una presencia divina, o sobrehumana, cuya realidad suele ser más bien inefable y cuya expresión visual o sonora estremece.

Edgar Allan Poe no es un escritor religioso en sentido estricto, mas su obra no está exenta de atisbos de una abrumadora presencia divina. Su narrativa y universo poético ciertamente participan de lo que algunos autores han calificado como "terror religioso" (Ingebretsen 1996). Aquí me interesa explorar la atemorizante presencia de lo numinoso en la obra de Poe. Al mismo tiempo, me interesa examinar la relevancia del concepto del silencio divino en conjunción con la transición hacia la muerte. Todo esto

\footnotetext{
${ }^{1}$ Este ensayo es una versión más elaborada de una ponencia que, bajo el título de "El silencio de Poe o los ecos de Dios", presenté durante el Coloquio Poe, el genio de lo perverso (FFyL-UNAM, 11-13 febrero de 2009).
} 
nos conduce hacia regiones liminales y umbrías. Como punto de partida, me enfocaré en un poema y un relato, ambos intitulados "Silence", y en el cuento "Shadow-A Parable". Mi análisis, sin embargo, me obligará a hacer referencia a otros textos también. La exploración de estos textos ayudará a entretejer una lectura comprensiva de la poética del silencio en la obra de Poe, una lectura que permita escrutar el poder del silencio y la inquietante resonancia de lo numinoso en su ars poética a través del "imperio de la imagen de la Muerte en el alma de Poe" (Bachelard, 1997: 91).

En su Das Heilige, o Lo santo, Rudolph Otto describe a la divinidad en su aspecto más absoluto como lo numinoso, cuya naturaleza lo convierte en el máximo misterio. Al restarle el componente moral a la categoría de "lo santo", nos encontramos con la idea de lo "numinoso", cuya experiencia resulta por naturaleza inefable (Otto, 2001: 14-15). Dios, en esa forma que trasciende nombres y manifestaciones, constituye la realidad suprema que provoca estremecimiento y que conmociona. La presencia de lo numinoso en Poe resulta bastante cercana a la descripción de Otto, como buscaré mostrar en las siguientes páginas. En ambos autores, la cuestión del numen obvia cualquier cuestionamiento ético; en Poe, además, ello contribuye a configurar una poética del silencio que, más que sólo callar, parece susurrar su angustia.

Lo numinoso, así pues, posee tres características principales: a) es el mysterium tremendum, en tanto constituye la inaccesibilidad absoluta, la capacidad de perturbar e inquietar; b) posee majestas, es decir, la potencia, la prepotencia y la omnipotencia que lo convierten plenamente en el Señor que está por encima de todas las cosas y las criaturas; c) posee también orgé, o energía, facultad sin la cual no sería capaz de crear (Otto, 2001: passim). La característica de mysterium tremendum se manifiesta en particular cuando hablamos de la "ira de Dios" que, sin ser necesariamente un acto maligno o negativo, no deja de estremecer y suele ser insondable. En la Biblia, el aspecto de lo numinoso cobra manifestaciones inequívocas, por ejemplo, a través de la aparición de Yahvé como la zarza ardiente en Éxodo o su idiosincrasia y parlamento en el Libro de Job. Su majestad, o potencia, supone siempre una desvaloración del yo: el sujeto ante la divinidad —en tanto criatura, es decir, producida por el Creador-, debe reconocer su inferioridad. La energía de la divinidad lo faculta para crear y destruir, 
producir objetos y cataclismos, proporcionar revelaciones visuales u orales y también el silencio profundo de la existencia.

Ahora bien, en tanto mysterium tremendum, la sustancia divina permanece inaccesible e indescifrable, como a veces sucede cuando nos preguntamos con el (verdadero) contenido de una pieza de la obra poesca. Además, Poe suele indicar que la experiencia numinosa va acompañada de una merma de la facultad oral y que la palabra poco a poco sucumbe ante el silencio. De este modo, nos encontramos con que la ausencia (de sonido) vehicula una presencia (el numen) cuyos sombríos ecos ponen en entredicho el sentido mismo de la existencia.

Lo que quiero destacar es el hecho de que el significado que el silencio tenía para Poe trasciende el meramente lingüístico y adopta tintes numinosos. ${ }^{2}$ Como ha señalado Dwayne Thorpe (Carlson, 1996: 94), el tema de la incapacidad de las palabras y la consiguiente necesidad de idear estrategias sugestivas son característicos de la poética de Poe. Esto, desde luego, está en armonía con la teoría del efecto que tanto defendió el escritor bostoniano. En un sentido muy preliminar, el silencio para Poe es correlativo con la muerte y/o la cesación de la existencia: "To meet the bodiless Silence is to encounter non-being" (Halliburton, 1973: 118). A veces, en la poética de Poe el silencio puede adoptar la forma del eco, esa paulatina evaporación del sonido en silencio; de ahí el reiterado uso de la repetición en la retórica de Poe. Es por esto que en "The Raven" la repetición lírica está fuertemente asociada con la muerte (Fried, 1986: 624). El eco y la repetición convergen en un umbral fonético pero también existencial, una región donde el sonido va perdiendo su materialidad y va poco a poco cediendo ante el silencio. Se trata de lo que aquí denomino una hipnosis fónica o resonancia numinosa y sombría. La región liminal a la que me he referido evoca también el símbolo de la sombra, imagen no plenamente definida y que juega un papel preponderante en el imaginario de Poe.

Con frecuencia en la obra poesca, la sombra puede representar un estado por el cual hay que transitar (Williams, 1985: 623). El silencio en estos

\footnotetext{
${ }^{2}$ Resulta interesante que en sus anotaciones sobre Poe, Fernando Pessoa destacara justamente el papel del silencio. Para Pessoa, la facultad auditiva estaba estrechamente relacionada con el temor y con lo grotesco en la obra de Poe (cf. George Monteiro, "Poe/ Pessoa." En Comparative Literature 40, 2 (Spring, 1988: 134-149).
} 
textos es una representación del no-ser en confrontación con el ser y, en conjunción con la sombra implica lo que Otto (2001: 38) caracteriza como "el noble terror que despierta lo numinoso". De algún modo, ello sugiere una doble naturaleza del Silencio. Quizá la fábula y el soneto titulados "Silence" justamente corresponden a cada una de estas naturalezas, al mismo tiempo que evocan una numinosidad inquietante.

\section{Silencio e hipnosis fónica}

El relato "Silence-A Fable" se desarrolla en torno de la confrontación entre dos entidades incorpóreas, a saber: la Desolación y el Silencio. Tal parece que este silencio dramático representa la Voz enmudecida de Dios. Pero ¿cómo opera y qué sugiere la relación entre sonido y silencio, materialidad e inmaterialidad en esta narrativa? En principio, las concepciones de Poe no están desligadas de las teorías pitagóricas acerca de la "música de las esferas", es decir que el equilibrio universal depende de la sintonía celestial de los astros. Ello, empero, no resuelve el problema del todo. Aquí lo que me preocupa primero es el silencio, más que el ruido. A diferencia del ruido - la cacofonía cósmica-, el silencio no es la deformación del sonido, sino su anulación. Un fragmento del largo poema "Al Aaraaf" (circa 1929) enuncia lo siguiente:

A sound of silence on the startled ear Which dreamy poets name "the music of the sphere."

Silence is the voice of God

Ours is a world of words: Quiet we call

Silence-which is the merest word of all.

All Nature speaks, and ev'n ideal things

Flap shadowy sounds from visionary wings-

But ah! not so when, thus, in realms on high

The eternal voice of God is passing by,

And the red wings are withering in the sky!

Según el poema, a Dios le corresponde el silencio; a nosotros, el sonido (las palabras). Los versos 126 a 128 sirvieron de epígrafe original justamente a la "fábula del silencio" en sus primeras versiones de 1832- 
1840. ${ }^{3}$ En el soneto que lleva el mismo título, Poe explica con un poco más de detalle la naturaleza de este silencio, mientras que en el relato nos enfrentamos no a su descripción, sino a su manifestación. En "Silence-A Sonnet", leemos:

There is two-fold Silence-sea and shore-

Body and Soul.

Más adelante en el poema, la voz poética nos apremia a no temer a este Silencio; antes bien, nos insta a rendirnos ante él de manera plácida (regresaré al poema más adelante). Sin embargo, en la "fábula" el silencio no produce tranquilidad y sosiego, sino terror puro y desconsuelo.

En este sentido, existe un puente donde el silencio y el ruido parecen converger, ambos en oposición al equilibrio pitagórico. Ahora bien: al mismo tiempo que la dialéctica del sonido/silencio cumple un papel toral en la fábula, la presencia divina, aunque nunca manifestada del todo, resulta esencial; como señala William Goldhurst: "The many religious references in the tale (...) suggest a religious theme in which the spirit of Man confronts divine silence" (Carlson, 1996: 151). Es decir que la tensión sónica dimana de una experiencia numinosa insoslayable Se trata de un silencio tan absoluto que resulta perturbador, un "sonido de silencio en el oído estremecido" como expresa el verso 124 de "Al Aaraaf" - que causa un terrible ruido ontológico, por así decirlo. Así, no se trata de una mera representación de la metafísica alemana y el "mórbido espiritualismo" que estaban de moda en la época (Sova, 2007: 160). Un indicio claro de que en "Silence" estamos lidiando con una lectura simbólica del poder numinoso del silencio se halla en el último libro bíblico: "Cuando [el Cordero] abrió el séptimo sello, se hizo silencio en el cielo como por media hora" (Apocalipsis 8: 1). Éste es el tipo de contexto que enmarca al relato poesco.

Rudolph Otto (2001: 95-96) apunta que el arte de Occidente posee básicamente dos modos directos de representación de lo numinoso: la oscuridad y el silencio, que en definitiva son de carácter negativo (son, respectivamente, la negación de la claridad y del sonido). En los textos que

${ }^{3}$ Entre 1840 y 1842 Poe cambiaría el título - “Siope" por "Silence" - y el epígrafe, además de realizar algunas correcciones textuales; para mayor información, véase Cantalupo, 1995: 1-2. 
analizaré en estas páginas encontraremos un impulso simbólico por negar la visibilidad y el habla. Las sombras, además, servirán en Poe como una especie de metáfora del eco, el cual habrá de producir un efecto alegórico e hipnótico.

Aunque no es una de las creaciones de Poe más renombradas y conocidas, "Silence-A Fable" ciertamente es una de las más interesantes y enigmáticas. ${ }^{4}$ De ningún modo desmerece ante los otros cuentos más reputados; tal vez incluso encierra mayor profundidad y riqueza interpretativa que varios de aquéllos. Antes mencioné que la fábula "Silence" abre con una cita del poema "Al Aaraaf". No obstante, hacia 184042 Poe sustituyó el epígrafe original con una cita del poeta griego Alcmán: "The mountain pinnacles slumber; valleys, crags and caves are silent" ("Las cumbres montañosas dormitan; valles, riscos y cuevas están en silencio"). "Silence-A Fable" posee un ambiente desconcertante y sobrenatural que nos sobrecoge. Ya desde las primeras palabras queda establecido el carácter perturbador del texto: "Listen to me", said the Demon, as he placed his hand upon my head. "The region of which I speak is a dreary region in Libya [...]" (Silence $§ 1){ }^{5}$

La lógica del texto nos refiere que la fábula propiamente dicha fue contada por el Demonio al propio narrador. La fantástica y bizarra historia cuenta cómo un hombre se posa sobre una suerte de roca mística y contempla la desolación en torno de él, al tiempo que el Demonio intenta atemorizarlo y hacerlo huir despavorido.

\footnotetext{
${ }^{4}$ La falta de atención al relato "Silence" —y lo mismo vale para "Shadow" — queda evidenciada por las poquísimas páginas que se le dedican en la mayoría de estudios sobre Poe; a veces, de hecho, ni siquiera se le menciona (cf., por ejemplo, los índices analíticos de Carlson 1996, Hayes 2004, Bloom 2006 y Sova 2007, obras recientes que, de alguna forma, ejemplifican las tendencias académicas en torno de Poe).

Entre los pocos trabajos dedicados a "Silence" o "Shadow" se encuentran Williams 1985 y Cantalupo 1995 (un interesante, aunque brevísimo escrito de cuatro páginas). Otros trabajos relacionados son: Joseph DeFalco, "The Source of Terror in Poe's 'Shadow-A Parable" en Studies in Short Fiction 6 (1969): 643-48; Benjamin F. Fisher, "The Power of Words in Poe's 'Silence'"' en Poe at Work: Seven Textual Studies, ed. B.F. Fisher (Baltimore: The Edgar Allan Poe Society, 1978), pp. 56-72; Burton Pollin, "Poe's 'Shadow' as a Source for His 'The Masque of the Red Death'", en Studies in Short Fiction 6 (1968): 104-107; y Alexander Hammond, "Further Notes on Poe's Folio Club Tales" en Poe Studies 8 (1975): 38-42 y "A Reconstruction of Poe's 1833 Tales of the Folio Club" en Poe Studies 5 (972): 25-32. Por desgracia, no me ha sido posible consultar dicho material.
} 
Sobre una faz de la roca se registran los siguientes caracteres: DESOLATION (Silence §5). El Demonio maldice a la flora y a la fauna para que se violenten mientras él permanece escondido entre los lirios acuáticos. La desolación se acrecienta, mas el hombre permanece incólume. El Demonio fracasa en su intento dos veces y al final recurre al "maleficio" del Silencio. Entonces, el Silencio se asienta por todas partes: en el aire y el agua, en los animales y los lirios; todo deviene inmóvil. El hombre tiembla entonces de terror, bajo una luna roja, y sale corriendo, dejando atrás la roca cuyos caracteres ahora rezan: SILENCE (Silence \$11). Después, al terminar su relato, el Demonio irrumpe en carcajadas, a las que no se une el narrador. Indignado, el personaje luciferino lo maldice y se sumerge entre las catacumbas, donde al final un lince intercambia una intensa mirada con el Demonio (\$13).

Para poder apreciar un texto como "Silence", es importante valorar correctamente las nociones de unidad, de contexto y de espacialidad. Como señaló Hartman, la "atmospheric unity is achieved through a unique correlation between observer and setting and/or participant in the story and the environment with which he interacts". Además, agrega, el recurso técnico para establecer dicha correlación se apoya en: "the stylization and circumscription of space, and the arrangement of individual details within patterns of orientation such as east-west, above-below, outside-inside, and so forth" (Hartman, 1979: 1). En la fábula de Poe, sin duda existe una imbricada correlación entre el escenario y los participantes de la historia, uno de los cuales también es espectador. La técnica más o menos se repite en distintos otros textos.

El cuento parecer adquirir tintes de una fábula profética e incluso posee ciertos ecos del Ezequiel bíblico que presagia tiempos apocalípticos. En el párrafo inicial de la primera versión de "Silence", Poe escribe acerca de la región que describe el Demonio, la 'dreary region in Lybia by the borders of the river Zäire':

...if by any chance thou hast beheld it, it must have been in one of those vigorous dreams which come like the Simoom upon the brain of the sleeper who hath lain down to sleep among the forbidden sunbeams among the sunbeams, I say, which slide from off the solemn columns of 
the melancholy temples in the wilderness. [Siope §1; itálicas en el original.]

La analogía entre el Simún y esos "sueños vigorosos" acentúa el tono catastrófico que caracteriza la narrativa de Poe. Este pasaje sería borrado en las versiones posteriores y definitivas de la fábula, pero contribuiría a hacer del texto una especie de pieza poética; más un poema en prosa que un mero relato. Al leer el texto, uno tiene la sensación de estar leyendo un poema, a causa de una cadencia rítmica constante y casi hipnótica. Un ejemplo es la repetición de la frase: "And there is no quiet... nor silence" (Silence §1, §3). Otras palabras y/o frases también tienden a la recurrencia, siempre al final de un párrafo, lo que las hace homólogas a un estribillo: "And the man trembled in the solitude: but the night waned, and he sat upon the rock" (Silence \$7-10). La iteración se mantiene hasta que el silencio irrumpe y ahuyenta al hombre.

Debra Fried ha sugerido que la repetición en algunos autores evoca a los epitafios que advierten sobre la inexorable llegada de la muerte. Desde la perspectiva de las inscripciones en lápidas y su correlación con autores como Kipling, Whitman y Poe, Fried (1986: 615) opina que los estribillos pueden ser empleados como un modo de emular la tendencia que tienen los muertos (o prontos por fallecer) de propiciar que se les recuerde. De manera significativa, ello también construye una suerte de diálogo entre los muertos y los vivos, un motivo en particular relevante dentro de la poética de Edgar Poe. Así, "Silence-A Fable" es un relato que leemos (un diálogo), pero es un relato que el Demonio contó al narrador (segundo diálogo). Un tercer diálogo es el que, a nivel simbólico, sostienen la Desolación y el Silencio.

La imperturbable actitud del hombre de toga en esta fábula—su impasibilidad casi intacta- es donde de hecho recae el meollo del asunto. La idea de que el hombre permanece quieto, sin que nada lo moleste sino hasta que el silencio se hace presente, es el aspecto esencial de la fábula. Aquí resulta pertinente la idea de que "Natural objects come to reflect psychic processes and moral problems [...]. At the same time, the analogy between inside and outside is also applied to the work of man [...] which now can directly reflect his countenance and his soul" (Hartman, 1979: 2). No hay que perder de vista que el hombre se encuentra como sumido en una especie de hipnosis a causa de los sonidos que lo rodean antes de temer ante 
el silencio. Hay quien sugiere que el hombre en prendas romanas podría ser una interpretación alegórica de la tentación de Satanás a Cristo en el desierto (cf. Carlson, 1996: 150). La interpretación es parcialmente aceptable, pero no resuelve del todo la desazón y el enigma. En concreto, la presencia numinosa no se encuentra expresada por el hombre de toga, sino por el Demonio y el silencio. ¿Cómo, pues, se conjugan los distintos elementos del relato para articular la resonancia numinosa?

La respuesta, en parte, está mediada por la naturaleza inequívocamente numinosa del texto. A través no sólo de la trama, sino también de la retórica misma, Poe pone de relieve la agencia del mysterium tremendum, aquí tal vez en sus grados más "puros y transfigurados". Otto escribe que el tremendo misterio se puede manifestar en formas feroces y demoniacas (como el Demonio y la maldición en "Silence", la Sombra en "Shadow" y la Peste en "The Masque of the Red Death") y que: "puede convertirse en el suspenso y humilde temblor, en la mudez de la criatura ante... —sí, ¿ante quién?-, ante aquello que en el indecible misterio se cierne sobre todas las criaturas" (Otto, 2001: 22). En "Silence", el hombre de toga —si bien posee un rostro con "rasgos de una deidad" (Silence §6) — no encarna a ningún numen, sino que es él quien experimenta el tremor divino

Ahora bien, si el texto en cuestión es una fábula, entonces en principio debe tener una moraleja. Pero ¿cuál es? ¿Qué es lo que Poe intenta exponer en esta extravagante y lúgubre fábula? Coincido con R. Benton en que el relato lidia, de manera alegórica, con la angustia del ser, de la existencia (Carlson, 1996: 123). Pero, aunque se trata de una fábula, no debemos esperar encontrarnos de manera directa y obvia con una moraleja. En otras palabras, en las fábulas literarias el "mensaje" no necesariamente está expresado en una fórmula verbal, sino que puede estar "encarnado" o "personificado", como ha sugerido H.J. Blackham (Cantalupo, 1995: 4, n.1). ¿Cómo se desarrolla tal conflicto?

Evidentemente, los dos polos sobre los cuales descansa la tensión narrativa del texto son la Desolación y el Silencio; allí yace el nodo crucial. De acuerdo con David Halliburton (1957: 135), la Desolación representa "el primer estado del ser humano" y el Silencio "la condición final que debe enfrentar". La tesis de Halliburton no me parece del todo convincente, pues 
no termina de cuajar. Si consideramos Eureka, el famoso tratado de Poe sobre la esencia del mundo, encontramos que Poe establece algunos principios de la Unidad, y que toda la materia transita de la unidad primordial a la desunión y de vuelta a la unidad. De este modo, si el silencio constituye el último estadio del hombre, también es el primero según los principios de Poe. La Desolación no puede ser tan sólo un estado del ser precursor, inicial y definitivo porque "Al crear al hombre libre (...) Dios introduce el silencio como factor inevitable de incertidumbre y ¿qué tanto de esta ausencia de palabra, de este cansancio del lenguaje, no lleva la impronta del mal y, por consiguiente, del sufrimiento, de la muerte?" (Cohen, 1996: 79).

Vale la pena considerar que en tanto carencia de sonido, el silencio supone una negación, una ausencia. Benton sugiere que el hombre en toga huye porque, después de que los caracteres en la roca mutan en SILENCIO, se percata de que el ser y la nada pueden llegar a fundirse (Carlson 1996: 123). Llevado al plano escatológico, el silencio determinaría una suerte de nada o vacío, tal y como lo entiende María Zambrano (1993: 180):

La nada muestra (...) su condición de "viviente" al cambiar de lugar, según cambia el proyecto de ser del hombre; según que el hombre pretenda o no ser y según lo que pretenda ser y cómo. Es la sombra de Dios; la resistencia divina. La sombra de Dios que puede ser simplemente su sombra — su amparo- o su vacío en las tinieblas contrarias.

En esta cita he añadido un énfasis que resultará crucial más adelante en este trabajo. Por ahora baste decir que el silencio en Poe expresa una fobia del autor por el estado de no-ser o vacío absoluto, un estado que el contacto con lo divino puede producir, ya sea de manera directa o indirecta, como sucede con las sombras o los ecos. En todo caso, en los textos que aquí discuto existe un persistente temor hacia la muerte.

La muerte en el cuento "Silence" está de algún modo prefigurada en las aguas del río Zaire. Aunque en un inicio "no hay ni quietud allí, ni silencio", tal es el destino. Al analizar el papel de las imágenes acuáticas en la poética de Poe, Bachelard advirtió que éstas tienden a la pesadez, rasgo que el crítico francés asoció con la muerte. De acuerdo con él, en Poe el agua "es un superlativo, una especie de sustancia de sustancia, una sustancia madre" (Bachelard, 1997: 75). Aunque sin ser equivalente a la idea 
heracliteana del devenir, las aguas pueden sugerir la procesión del ser dentro del mar de la existencia. Por ello, el agua "proporciona el símbolo de una vida especial atraída por una muerte especial" (ibíd.: 78). El hombre vestido en toga, y con su rostro cuyos "rasgos eran los rasgos de una deidad", habrá de encarar un acontecer que haga justicia a su aspecto divino.

En un punto, Bachelard (1997: 108) equipara el murmullo de las aguas y los lirios a la voz del remordimiento, voz que ha de ser acallada. La lectura aquí no me parece adecuada. De ser así, ¿por qué el hombre, al hacerse el silencio en las aguas (que fungirían como una proyección de su inconsciente), habría de correr lleno de miedo? Una victoria sobre el remordimiento más bien habría de provocar alivio, aun si es falso o temporal. Esta clase de silencio, aunque carente de un mensaje verbal, ofrece significados sutiles. Son sutiles porque, en la medida en que atañen al ámbito de lo numinoso, resultan inefables. La naturaleza divina y la vida más allá de la muerte - habitaciones de la morada numinosa- no se pueden explicar de modo directo: "En nosotros el silencio es el efecto inmediato que produce la presencia del numen" (Otto, 2001: 97). Las palabras humanas son incapaces de describir estas regiones, estas experiencias. Por eso lo religioso también aterra, más allá de sus promesas de salvación y serenidad. Al menos parcialmente eso es lo que encontramos en "Silence-A Fable".

Aquí me gustaría hacer una sugerencia. Visualmente, la imagen del hombre sobre la columna de roca recuerda a las torres del silencio del zoroastrismo. No es de sorprender que estas edificaciones posean una función mortuoria. Puesto que los cadáveres se consideran impuros, la práctica parsi busca evitar que éstos contaminen al resto de los elementos. Así, los cadáveres se arrojan dentro de estas torres a las que no puede asistir nadie que no esté autorizado: los cuerpos serán consumidos por los buitres. La sugerencia no es tan gratuita como parece a simple vista: hacia el final del relato, el narrador compara la narración que le ha hecho el demonio con los relatos en los libros de los Magos (the Magi). El término originalmente se refería a los sacerdotes zoroástricos, que eran famosos por adivinar el futuro, leer los astros y otros actos de destreza mágica. A juzgar por las propias 
referencias de Poe en títulos, notas y vocabulario (notablemente "arabesque"), no parece difícil que él haya tenido cierto conocimiento de algunas culturas de Asia y Oriente Medio: "Silence", de hecho, se sitúa en Libia y el narrador parece provenir de la cultura islámica: "but, as Allah liveth, that fable which the demon told me as he sat by my side in the shadow of the tomb, I hold to be the most wonderful of all" (Silence §13). Además, menciona a los genios, figuras prominentes en el zoroastrismo y el Islam popular. Al final, todos los elementos contribuyen a crear la sensación final de extrañeza.

Ahora bien, la incapacidad por expresar la experiencia de lo numinoso quizá está simbolizada por el lince que al final del relato mira fijamente a los ojos del Demonio. Esta imagen incierta e inquietante deja al lector incómodo y perplejo. Después de esta descripción ya no hay más que leer. Es como si el texto mismo se sumiera en las profundidades y nosotros en el silencio.

Siope - el título original de la fábula de Poe- es una palabra griega que quiere decir "silencio". ${ }^{6}$ No sería extraño que tuviese ecos bíblicos. En los evangelios, Lucas utiliza justamente esta palabra para referirse al silencio que Zacarías tuvo que padecer durante nueve meses. El arcángel Gabriel le anuncia a Zacarías que él y su esposa, aunque ya entrados en años, tendrán un hijo. Zacarías no cree en las palabras del mensajero divino y como consecuencia éste lo condena a quedar sumido en el silencio hasta que se concrete el nacimiento del niño (Lucas 1: 18-20). ¿Acaso el cuento de Poe podría leerse como una especie de parodia fantasmagórica del relato bíblico? De ser así, el Demonio sería una encarnación de Gabriel y el hombre de toga, de Zacarías. El marco narrativo, sin embargo, difiere de manera importante, aunque no deja de ser significativo - y aun irónico- que sea precisamente el arcángel Gabriel (emisario de la palabra) quien perpetre una maldición del silencio. De manera similar, en "Silence" el Demonio, un personaje que suele vociferar, recurre al silencio y, al final del relato, el lince le replica con un silencio aún más inquietante.

Barbara Cantalupo (1995: 1) sugiere que interpretemos al lince no sólo como un símbolo animal, sino en tanto palabra. Así, la voz inglesa lynx (lince) estaría evocando su homófono links (vínculos). De acuerdo con Cantalupo, esta función copulativa — fónica y semántica— refiere al "poder de las palabras", una frase que Poe utilizó como título de otro relato en 1945, 
época en que Poe parece haber estado particularmente obsesionado con su poética del silencio. Poe establece, pues, una analogía entre mundo y texto: un texto está poblado de imágenes y palabras y el mundo puede ser leído e interpretado. Cantalupo (1995: 3) opina que el lince podría funcionar como un símbolo de posibilidad (el demonio mismo queda perplejo ante el silencio del felino y, por ende, mermado). De esta forma, acaso el lince implique la posibilidad de poder leer e interpretar el relato, pero también de descifrar el mundo, mediante una valoración de la dialéctica del silencio y de la hipnosis fónica. Ello está en consonancia con "Al Aaraaf", poema con el que comencé este apartado y el cual expresa que si el silencio le corresponde a Dios, a nosotros nos corresponde "un mundo de palabras".

La fábula posee una reformulación posterior en un poema que lleva el mismo título: "Silence". Este poema fue compuesto en 1839 bajo el título de "Silence, a Sonnet" y hacia 1843 cambió a "Sonnet-Silence", aunque sin cambios drásticos en cuanto a estructura. Uno de los cambios significativos se refiere al reemplazo de $\operatorname{dim}$ ("oscuro") por lone ("solitario") en el verso 14. Con frecuencia este poema homónimo se ha considerado uno de los más indescifrables de los que compuso Poe. Aunque podría no ser obvio, naturalmente ambos textos (la fábula y el soneto) poseen una fuerte conexión entre sí y, de algún modo, se complementan. En el poema encontramos una manifestación inquietante de la dualidad ser/no-ser, un poco en relación con la disociación entre el cuerpo y el alma. Aunque por lo general Poe se ceñía al soneto shakespeareano, en este poema trabajó una variación del soneto italiano (Mabbott, 1969). El poema íntegro, en su versión definitiva, es el siguiente:

There are some qualities-some incorporate things, That have a double life, which thus is made A type of that twin entity which springs From matter and light, evinced in solid and shade. There is a two-fold Silence — sea and shore-

Body and Soul. One dwells in lonely places,

Newly with grass o'ergrown; some solemn graces, Some human memories and tearful lore, Render him terrorless: his name's "No more". He is the corporate Silence: dread him not! 
No power hath he of evil in himself:

But should some urgent fate (untimely lot!)

Bring thee to meet his shadow (nameless elf,

That hauntheth the lone regions where hath trod

No foot of man), commend thyself to God!

Desde los primeros versos del soneto se puede percibir una atmósfera extraña y casi siniestra, algo que atañe al ámbito de lo sobrenatural. Las referencias a la materia y la luz, lo sólido y la penumbra, nos sitúan en un ambiente liminal una vez más. Para algunos, el soneto versa sobre la oposición entre la muerte corporal y la muerte del alma, mientras que otros ven en el poema un "intento romántico" de "introducir al sonido algo más que el sonido" (Carlson, 1996: 93-94). Dawn Sova, por ejemplo, opina que el mensaje del soneto es que debemos aceptar como natural la muerte del cuerpo y a "No more" como un nombre de ésta; en contraparte, la muerte del alma ha de atormentarnos por toda la eternidad (Sova, 2007: 161).

El silencio parece poseer la capacidad de hacerse presente en ambos lados del umbral de la muerte. John Phelps Fruit señala que "Poe was deeply impressed with the idea of Silence as the eternal voice of God, as the music of the spheres" (Mabbott, 1969: 320). La casi muda "música de las esferas" orquestra el equilibrio cósmico que impera entre los planetas, un perfecto y armonioso orden que rige el universo y al mismo tiempo sugiere la posibilidad de una hipnosis fónica. Pero es menester que dentro de este complejo exista la posibilidad de la irrupción. Ya antes que Poe, algunos autores norteamericanos —como el predicador religioso Jonathan Edwards- habían elaborado un imaginario en que se alternan la desesperación, la incitación y el equilibrio cósmico (Ingebretsen, 1996: 100-1).

La fascinación por este tipo de teorías deriva en una línea constante a veces implícita, a veces explícita, que apunta hacia cierto "equilibrio" metafísico o cósmico. Tal es lo que encontramos en poemas como "Al Aaaraaf" o "The Conqueror Worm", así como en las tres "conversaciones", a saber: "The Conversation of Eiros and Charmion", "The Colloquy of Monos and Una" y "The Power of Words". "The Conqueror Worm" — que Poe más tarde insertaría en su cuento "Ligeia" - ha sido asociado con una tradición que data desde tiempos platónicos y atraviesa los periodos isabelino y 
jacobino; esta tradición utiliza pequeños dramas para re-crear el "teatro del mundo", una manera de expresar las pugnas de la vida dentro del marco de una óptica global teocéntrica (Lubbers, 1967: 376-77). El poema introduce a una multitud de ángeles que acude a presenciar un espectáculo:

An angel throng, bewinged, bedight

In veils, and drowned in tears,

Sit in a theatre, to see

A play of hopes and fears,

While the orchestra breathes fitfully

The music of the spheres.

La situación, al igual que en "The Masque of the Red Death" (1842/1845), está enmarcada dentro de la música de una orquesta (notablemente, ésta interpreta la "música de la esferas"). Como sea, en todos estos casos, en mayor o menor medida, existe la presencia o inferencia de una voz inasible para los mortales, al menos hasta el momento de la muerte. Es importante advertir que para Poe la muerte convencional no equivale a sumergirse en el no-ser. La vida, para él, depende de dos polaridades iguales y opuestas: el ser y el no-ser; ambos constituyen la "entidad doble" que señala el soneto "Silence" (verso 3). Así, hay dos tipos de muerte: la muerte corporal, donde no se pierde la esencia del ser, y la muerte del alma, que provoca el fin de la existencia.

El verso 13 de "Silence" menciona a una "sombra" que habrá de hacernos frente en el momento del fallecimiento corporal. ¿Quién o qué es esta sombra? En términos de un crítico, la sombra no es ni el punto terminal en el momento de la muerte biológica, ni un umbral que se teme o ansía (Williams 1985: 624). Buscar la respuesta nos conduce directamente a otra pieza de Poe: el relato intitulado "Shadow-A Parable", al que regresaré más adelante.

Hasta donde sabemos por el poema "Silence", ésta es la sombra del Silencio y su nombre, según revela el soneto, es "No more". Desde luego, el eco nos remite de inmediato a su más célebre poema, "The Raven" (1845). El "centro de gravedad" de este poema se sostiene en gran medida en la rima repetitiva de los sonidos -ore (m):[r]): No more, nevermore, Lenore, nothing more, before, explore, etc. En ese caso, la rima implica un sentimiento de 
fatalidad e inexorabilidad que no está ausente en "Silence-A Sonnet". Varios críticos han discutido la obsesión que Poe tenía por este sonido (cf. Mabbott, 1969: 204; Caputi, 1953: 173-74), pero ello no elimina el hecho de que esta resonante frase parece adquirir un contexto insondable, como si el incesante eco se fundiera eventualmente en los recodos del silencio, imprimiendo una estampa fatídica. La repetición -o el eco- avanza como una carga existencial y erige una suerte de sombra que opaca y acosa el alma (Fried, 1986: 628). Aunque los refrain de algunos poemas no están muy bien logrados (cf. Caputi, 1953), los pseudo-refrain en "Silence-A Fable" contribuyen a reforzar el entorno sofocante e inquietante que semeja el ambiente descrito en el soneto. Se trata de lo que Bachelard (1997: 75) ha caracterizado como una "monotonía genial" lograda a partir de la tonalidad del verbo, pero que yo prefiero llamar resonancia numinosa o hipnosis fónica.

Thomas Mabbott sugiere que Poe bien pudo haber tenido influencia de dos sonetos de Thomas Hood, un poeta y humorista británico coetáneo de Edgar Allan Poe. Los poemas en cuestión llevan por título "Silence" y "Death". De hecho, parece que más de una vez el soneto de Hood ha pasado por composición de Poe. El "Silence" de Hood comienza con los versos "There is a silence where hath been no sound / There is a silence where no sound may be / In the cold grave [...]", que bien podría haber tenido en mente Poe al componer su soneto. Significativamente, el inicio del poema de Hood también ofrece una repetición epitáfica. El otro soneto, "Death", menciona que "This eloquent breath shall take its speechless flight". Las nociones de muerte y silencio están presentes en estos dos poemas. No obstante, en el soneto "Silence" de Hood las palabras se conjuntan para construir un silencio extremadamente solitario y más bien auto-consciente:

But in green ruins, in the desolate walls

Of antique palaces, where Man hath been, 10

Though the dun fox, or wild hyæna, calls,

And owls, that flit continually between,

Shriek to the echo, and the low winds moan,

--There the true Silence is, self-conscious and alone.

Aunque en el texto de Poe se advierte una soledad similar, se expone una naturaleza divergente, una que se refiere a la doble naturaleza del 
silencio que, a su vez, corresponde con los estados de la existencia. No descarto la influencia temática (en el poema de Hood también se menciona a una sombra), pero hay que reconocer que el soneto de Poe acusa características propias que lo demarcan claramente de su contraparte en Hood. Aquí lo importante es resaltar el hecho de que Poe otorga un papel importantísimo al silencio, no sólo como una prerrogativa de la divinidad, sino también como preámbulo del abatimiento. Incluso valdría la pena considerar la posibilidad de que el lince en "Silence-A Fable" podría ser una reelaboración de la hiena que aparece en el poema de Hood: si ésta se asocia a una cacofónica risa, el lince de Poe mira en silencio. Poe podría estar de acuerdo con la idea de que "La economía general del universo, su equilibrio emocional, exigen que Dios calle. Y qué significa callar, qué el silencio, sino el dolor y la muerte" (Cohen, 1996: 77).

Acaso la "moraleja" de la "fábula del silencio" se escuche por aquí. En "Silence-A Fable", el hombre de toga sale huyendo sólo ante el silencio, no ante el caos. ¿Por qué le teme al silencio y no a la devastación? ¿Por qué preferir la turbulencia ante la quietud? Posiblemente porque la turbulencia y el caos suponen la vida terrenal, imperfecta como es. Aquí cabe hacer alusión a "The Masque of the Red Death". Al comentar sobre "The Masque", Sova (2007: 110) opina que "The ambiguity of the exact setting lends the story a mystical element and suggests that the author may have meant it to function as a parable or fable". De esta manera, Sova implícitamente vincula "The Masque" con "Silence" y "Shadow" gracias a una función alegórica que, desde mi óptica, articula la poética del silencio.

Los motivos del sonido y el silencio forman parte del artilugio narrativo que va construyendo el suspenso. Cada hora, el solemne reloj de ébano emite sus hondas campanadas, ante las cuales la orquestra no puede sino dejar de tocar; los danzantes, por su parte, se sumen momentáneamente en el desconcierto y la desazón. Eventualmente las campanadas forzarán un silencio total del cual surgirá la Peste, tomando la vida de cada uno de los invitados como si fuese un emisario divino de la muerte. 


\section{Sombras y resonancia numinosa}

Tierra de oscuridad, lóbrega como sombra de muerte, sin orden y que aparece como la oscuridad misma.

Job 10: 22

El silencio absoluto no puede venir sino de Dios, y el silencio de Dios promete mayores aflicciones que la Desolación. Es sólo a través del silencio que el hombre siente la presencia de Dios, y ésta es aterradora. Ahora bien: la anulación del sonido a menudo se equipara en Poe con la anulación de la visibilidad, el silencio o el eco con las sombras. En ambos casos, la situación suele producir un estremecimiento terrible. En "The Pit and the Pendulum" (1842/1845), el narrador, ya sentenciado, se encuentra recluido en un pozo:"So far, I had not opened my eyes. [...] I longed, yet dared not, to employ my vision. I dreared the first glance at objects around me. It was not that I feared to look upon things horrible, but that I grew aghast lest there should be nothing to see (Pit §5; énfasis en el original)."Resulta muy revelador que el narrador teme mirar hacia la oscuridad total, es decir, hacia la nada. Por fin, el protagonista reúne las fuerzas para abrir los ojos: "My worst thoughts, then, were confirmed. The blackness of the darkness seemed to oppress me and stifle me. I struggled for breath" (Pit §5). El terror que ello produce es análogo al que experimenta el hombre de toga en "Silence" (piénsese también en la angustia que experimenta el narrador de "Loss of Breath" al perder el habla)

Edgar Poe era una persona y un escritor obsesivo, así que su cosmogonía es prominente e imbuye su obra entera. He ido trazando ya algunas incidencias de ciertos motivos en distintos textos. "Siope", la primera versión de "Silence-A Fable", data de 1832; "Shadow-A Parable" fue escrito hacia 1835; cuatro años después vendría "Silence, a Sonnet". Quizá por tratarse de un texto posterior, en el soneto encontramos una exposición algo más detallada acerca del Silencio y la Muerte. La "parábola", en todo caso, es un texto menos enigmático que la "fábula", pero de ningún modo simple; aunque sólo consta de dos cortos párrafos (el contexto) y un 
último y largo párrafo (el relato propiamente dicho). Algunos estudiosos han interpretado este relato como un "serio y profundo comentario del poder de la Sombra de la muerte simbolizada para provocar terror y pavor en el corazón del hombre", como la representación de un rito de pasaje o purificación, o como una parodia de "ficciones trascendentales pseudopoéticas" (Williams, 1985: 631). ${ }^{7}$ En particular la última interpretación me parece errada. La obsesión de Poe por estos temas sugiere más el terreno de la escatología que el de la parodia.

Un pasaje bíblico afín a los textos que discuto en este trabajo se encuentra en el Libro de Job (4: 14-17): Sobrevínome un espanto y un temblor, que estremeció todos mis huesos. Y un espíritu pasó por delante de mí, que hizo que se erizara el pelo de mi carne. Paróse un fantasma delante de mis ojos, cuyo rostro yo no conocí, y quedo, oí que decía "¿Si será el hombre más justo que Dios?"

En contestación a los lamentos de Job, en este pasaje Elifaz relata una visión que tuvo: una forma fantasmagórica, amorfa e indefinida, se erige delante de él; Elifaz queda en silencio y se escucha una advertencia sobre el papel del hombre frente a la divinidad. El punto climático de la revelación numinosa vendrá de la voz del torbellino, en ese fabuloso poema laudatorio de la creación que hace a Job sumirse en el silencio: “Una vez hablé, y no responderé: aun dos veces, mas no tornaré a hablar". A continuación, Yahvé le replica "desde la oscuridad" (40: 5-6;). El silencio, el espectro amorfo, la oscuridad y el pavor también se conjugan en la narrativa de Poe para apuntar hacia una experiencia numinosa que, como en el Libro de Job, más que reconfortante resulta ser profundamente inquietante. En buena medida, "Shadow" es una adaptación de estas escenas.

La "parábola de la sombra" comienza con una cita del Antiguo Testamento: "Yea, though I walk through the valley of the shadow of death" ("Aunque ande en valle de sombra de muerte"; Salmos, 23: 4). La cita no figura en las versiones anteriores a 1842 y agrega un cariz interesante: en el texto bíblico - y según la traducción-, el verso puede referirse o bien a la muerte, o bien al camino de la perdición. Poe lo toma en su primera acepción en un nivel explícito y en su segunda acepción en un nivel tácito. La sombra del relato es, justamente, una manifestación de la muerte. Desde luego, la 
relación entre ambos cuentos ("Silence" y "Shadow") existe, aunque no resulta tan evidente a primera vista. El soneto, sin embargo, proporciona de forma manifiesta el eslabón al mencionar que la mancha oscura y espectral es la Sombra del Silencio, o del "Silencio colectivo", un "elfo sin nombre / que ronda las solitarias regiones que no ha pisado / hombre alguno" (vv. 1315). El soneto refiere, además, que existe un poder superior por encima de él que bien podría tratarse de una entidad numinosa.

Este oscuro elfo - la sombra - acorrala; viene de donde no ha caminado ningún hombre, ni podría hacerlo. La Sombra es el embajador de las más oscuras regiones de la muerte. En "Shadow-A Parable", Oinos -el personaje principal- se encierra en compañía de unos amigos para escapar de una plaga que asedia a la población, un motivo también trabajado en "The Masque of the Red Death". Se ha tapiado la entrada a la cámara donde se encuentran Oinos y sus compañeros, y éstos matan el tiempo recitando las canciones de Anacreonte. Tras morir uno de ellos, el grupo palidece pero intenta conservar la algarabía, si bien la penetrante presencia del difunto amigo los inquieta. Eventualmente, una mancha oscura se levanta entre el cadáver y los vivos; el terror se apodera de todos y Oinos, el narrador, le pregunta su nombre. La mancha responde: "I am SHADOW, and my dwelling is near the catacombs of Ptolemais, and hard by those dim plains of Helusion which border the foul Charonian canal (Shadow §3)."

Caronte, desde luego, es el barquero que custodia el río que debían cruzar los muertos en la mitología helénica. La Sombra, pues, se encuentra estrechamente vinculada con la muerte, pero también pone de relieve la impotencia que experimenta el individuo ante el numen: El sentimiento de criatura es más bien un momento concomitante, un efecto subjetivo; por decirlo así, la sombra de otro sentimiento, el cual, desde luego, y por modo inmediato, se refiere a un objeto fuera de mí (Otto 2001: 19; énfasis en el original).

El efecto subjetivo a que se refiere Otto queda reflejado en el cuento mediante la percepción única de Oinos: aunque son siete los amigos reunidos (más un difunto), nunca escuchamos los pensamientos de los otros seis.

Por otro lado, Defalco entiende "Shadow" como una alegoría acerca del cuerpo y el alma, en donde se pone de relieve la pérdida de la identidad 
individual durante la muerte, una idea que Poe desarrolló en Eureka (cf. Carlson 1996: 150-51). Hacia el final del cuento, la Sombra habla, mas: "the tones in the voice of the shadow were not the tones of any one human being, but of a multitude of beings" (Shadow §3). La Sombra, así, no es únicamente una manifestación de la Muerte, sino una suerte de encarnación de todos los muertos cuya vida ha cobrado. Este motivo refuerza la idea ya presentada en "Silence-A Sonnet", donde se califica a la Sombra como el "Silencio colectivo", pero también personifica la resonancia numinosa a la que me he referido antes y sobre la cual se fundamenta la poética del silencio. En lugar del verso de Salmos, Poe bien podría haber optado por utilizar como epígrafe a uno de los profetas: “Tu voz será como un espectro de la tierra, y desde el polvo tu palabra será como un susurro" (Isaías 29: 4). El pánico que experimenta Oinos evoca el estupor ante lo "absolutamente heterogéneo" del tremendo misterio (Otto 2001: 36-40), un misterio que en "Shadow" implica la visión pero que priva el habla. Se trata verdaderamente del terror religioso que produce el contacto con el Gran Otro, invisible por heterogéneo e indecible por tremendo.

En un cruel juego de espejos, los siete griegos reunidos en el relato emulan irónicamente a la multitud espectral que supone la Sombra: la voz de todos los difuntos, por tanto denominada "the corporate Silence". Esta colectividad es uniforme a través de la figura de la Sombra y de algún modo los siete borrachos sobrevivientes se unifican en Oinos. Todos, se intuye, habrán de perecer. Es importante advertir que el nombre de Oinos puede derivar al mismo tiempo de las palabras griegas para "vino" y para "uno". Los siete griegos recluidos están unificados por el vino, intentando olvidar las calamidades exteriores. Al final, sin embargo, lo que de verdad los une es la muerte. El motivo es característico de Poe: "Poe constructs his echo chambers to pick up and repeat the sounds of negation, death, denialendings that become protracted through repetition" (Fried, 1986: 626). Una vez más nos encontramos con la idea de una hipnosis fónica, sólo que en esta ocasión la iteración fónica no resuena sino que enmudece, como en realidad ha sucedido con la voz del propio Oinos. Lo que hay es una insistencia por preservar el sonido, una tentativa desde luego fallida. 
De entre todas las voces emitidas al unísono por la Sombra, Oinos reconoce la voz de amigos y parientes fallecidos. Esta emisión verbal tiene su contraparte en la casi frenética tentativa de Oinos y sus compinches por seguir cantando las canciones de Anacreonte. Poco a poco, las fuerzas van abandonando al grupo de bebedores y sólo va quedando el eco de las melodías. La antes "loud and sonorous voice" de Oinos va perdiendo terreno. Este cantar marchito adelanta la extinción de la vida, así como el chianti que beben recuerda cada vez más la sangre. El cadáver de su amigo se convierte, alegóricamente, en un reflejo anticipado de todos ellos, una imagen que todos quieren negar. De hecho, para Williams (1985: 628), la yuxtaposición del cadáver y la sombra sugiere una analogía con el "two-fold Silence" al que alude el soneto "Silence".

Sabemos que Oinos habrá también de sucumbir porque él mismo nos lo hace saber en el inicio del relato: "Ye who read are still among the living, but I who write shall have long since gone my way into the region of shadows" (Shadow §1). Sin duda, así fue. En el texto titulado "The Power of Words" nos encontramos de nuevo con este personaje, pero en una etapa posterior. Allí, Oinos y el alma de otra persona muerta sostienen un debate en torno de la naturaleza de la existencia, de la muerte y de la metafísica que rige a las palabras y la creación. Los tres textos "conversacionales" de Poe están dominados por inquietudes filosóficas y elaboran discursivamente sobre los puntos expresados narrativamente en los relatos "Shadow" y "Silence" que, para Carlson (1996: 150), constituyen grandes ejemplos del uso impresionista de las facultades imaginativas.

De hecho, no parece descabellado pensar que Poe haya interpretado imaginativamente el simbolismo del número 7 para reforzar su poética del silencio. En Apocalipsis, hay varios pasajes importantes en los cuales el siete va acompañado de un silencio absoluto, de un sonido celestial, de un anuncio cardinal y/o de connotaciones escatológicas, por ejemplo: "Ya no hay más tiempo, sino que en los días de la voz del séptimo ángel, cuando él esté por tocar la trompeta, también será consumado el misterio de Dios, como él lo anunció a sus siervos los profetas" (Apocalipsis 10: 6-7; ver también 8: 1, 11: 15 y 16: 17-18). La trama de "The Masque of the Red Death" se desarrolla a través de siete salones, al final de los cuales la última campanada del reloj de ébano celebrará el triunfo de la Muerte; en 
"Shadow", son siete los griegos sobrevivientes y cuyos cantos serán apagados por la Sombra.

Pero Oinos no debió haber muerto enseguida. Al menos contó con el tiempo suficiente para poder escribir su narración con un "estilete de hierro". Ello crea un interesante diálogo con el lector, lo que quiere decir una conversación entre los vivos y los muertos. Ambos, sin embargo, coinciden en un tiempo virtual, el del presente de indicativo que aplica tanto a "ustedes que leen" como a "pero yo que escribo". Dentro de este panorama, las palabras que Oinos escribe no son sino una variante del eco, una variante mucho más dramática puesto que carece por completo de sonido. En su encuentro con la Sombra, Oinos se queda sin habla - literalmente- y sus palabras ya sólo pueden ser leídas, no escuchadas. Estar muerto, en un sentido, es ser leído (Fried 1986: 617), de ahí la importancia del epitafio. Y el epitafio es el eco sombrío y mudo de los muertos.

La misma obsesión de "Shadow" y "Silence" parece adivinarse subrepticiamente en otros textos, como "The Pit and the Pendulum" (1842). En el primer párrafo de este cuento, el narrador relata su comparencia ante las autoridades de la Inquisición, quienes habrán de emitir su fallo. El atormentado narrador dice:

I saw the lips of the black-robed judges. They appeared to me whitewhiter than the sheet upon which I trace these words-and thin even to grotesqueness [...] I saw that the decrees of what to me was Fate were still issuing from those lips. I saw them writhe with a deadly locution. I saw them fashion the syllables of my name; and I shuddered because no sound succeeded. I saw, too, for a few moments of delirious horror, the soft and nearly imperceptible waving of the sable draperies which enwrapped the walls of the apartment (Pit $\S 1)$.

Desde luego, lo que destaca en primera instancia de este párrafo es la relación entre el color negro y la muerte (la sentencia de los inquisidores). Aquí llama la atención que, aunque vestidos de negro, le parecían blancos al enjuiciado. El carácter numinoso queda reflejado por el "horror delirante" del protagonista y por las figuras casi indefinidas que lo encaran. Parte del efecto que Poe trabajó en este cuento depende de la obsesión visual: todos los enunciados citados comienzan con "Yo vi", lo que habrá de contrastar 
dramáticamente con la oscuridad que rodeará al narrador (Pit \$5 en adelante). Tampoco parece casual la presencia de ropajes de color azabache (sable draperies), un motivo también presente en "Shadow" y "The Masque". Aún más significativo resulta el hecho de que el narrador nos revela que se encuentra escribiendo su relato, un motivo similar al de "Shadow": allí, sin embargo, Oinos no se librará de la muerte. Tampoco debemos perder de vista que la visibilidad en esta cita se encuentra en estrecha relación con el silencio.

La narración de “The Pit” sigue inmediatamente así:

And then my vision fell upon the seven tall candles upon the table. At first they wore the aspect of charity, and seemed white slender angels who would save me; but then, all at once, there came a most deadly nausea over my spirit, and I felt every fibre in my frame thrill as if I had touched the wire of a galvanic battery, while the angel forms became meaningless specters, with heads of flame, and I saw that from them there would be no help. And then there stole into my fancy, like a rich musical note, the thought of what sweet rest there must be in the grave (Pit $\S 1$ ).

Las siete grandes velas remiten al simbolismo manejado en "Shadow" y "The Masque": los griegos reunidos y las salas coloreadas de Prospero, pero también las siete velas en la ciudad de Ptolemais y los candeleros que iluminan las salas del príncipe. En "The Pit", los ilusorios ángeles se tornan en espectros $\mathrm{y}$, más que ofrecer un posible desasosiego, sellan el destino mortal del narrador. De pronto, las velas se sumen en la nada (nothingness) y la oscuridad lo cubre todo; como es de esperar: "Then silence, and stillness, and night were the universe". El silencio fatal ya había sido prefigurado con el "tono musical" que el narrador vincula con la tumba.

Una poética del silencio como la que he intentado desentrañar en este trabajo puede también ayudar a explicar por qué, por ejemplo, hacia el final de The Narrative of Arthur Gordon Pym (1937-38) el entorno cada vez se torna más ominoso al mismo tiempo que emblanquece... no que ennegrece:

March 21 A sullen darkness now hovered above us - but from out the milky depths of the ocean a luminous glare arose, and stole up along the 
bulwarks of the boat. We were nearly overwhelmed by the white ashy shower which settled upon us and upon the canoe, but melted into the water as it fell. The summit of the cataract was utterly lost in the dimness and the distance.

Una vez más encontramos imágenes recurrentes. A los colores blanco y negro, a la luminosidad y la penumbra, habrá también de sumarse las corrientes de un cuerpo de agua, una figura envuelta y la muerte:

March 22 The darkness had materially increased, relieved only by the glare of the water thrown back from the white curtain before us. Many gigantic and pallidly white birds flew continuously now from beyond the veil, and the scream was the eternal Tekeli-li! as they retreated from our vision. Hereupon $\mathrm{Nu}-\mathrm{Nu}$ stirred on the bottom of the boat; but, upon touching him, we found his spirit departed. And now we rushed into the embraces of the cataract, where a chasm flew itself open to receive us. But there arose in our pathway a shrouded human figure, very far larger in its proportions than any dweller among men. And the hue of the skin of the figure was of the perfect whiteness of the snow.

Lejos de sorprender, el ambiente numinoso impera en esta escena final de la saga de A.G. Pym. No parece descabellado concebir esta escena como una reescritura del desenlace de "Shadow": allí también un grupo de sobrevivientes, aislados, atestigua primero la muerte de uno de ellos y luego la emergencia de una inquietante figura que, en el caso de Pym, es muda y de color blanco. Hay que reparar también en el papel que juegan los extraños pájaros, los cuales, como las velas en "The Pit", más que augurar caridad, decretan la fatalidad. Por un lado, con sus "eternos gritos" las enormes aves blancas recuerdan el incesante nevermore del cuervo, una asociación relativamente evidente; pero por otro lado, las aves también emulan a los lirios que en "Silence-A Fable" también están vinculados con el agua:

For many miles on either side of the river's oozy bed is a pale desert of gigantic water-lillies. They sigh one unto the other in that solitude, and stretch towards the heaven their long and ghastly necks, and nod to and fro their everlasting heads. And there is an indistinct murmur which 
cometh out from among them like the rushing of the subterrene water. And they sigh one unto the other (Silence §2).

El murmullo que las aguas del río y los lirios acuáticos emiten representa una variante de la resonancia numinosa, un eco que desembocará en el Mar de la Muerte. Éstas son aguas que no fluyen, sino que "palpitan por siempre y por siempre bajo el rojizo ojo del sol con un movimiento tumultuoso y convulsivo". Se trata, pues, de aguas moribundas. En el bosque que yace a orillas del río encontramos una vegetación incómoda, ominosa. En el cielo, las nubes grises se precipitan ruidosamente hacia el horizonte, como una catarata. En ese sentido se puede reconocer que las aguas poseen un objetivo claro: "absorber las sombras, ofrecer una tumba cotidiana a todo lo que, cada día, muere en nosotros" (Bachelard, 1997: 89). La asociación implícita entre el agua, el murmullo (variante del eco que conduce al silencio) y la muerte figura también en "Eleonora" (\$4):

From the dim regions beyond the mountains at the upper end of our encircled domain, there crept out a narrow and deep river, brighter than all save the eyes of Eleonora; and, winding stealthily about in mazy courses, it passed away, at length, through a shadowy gorge, among hills still dimmer than those whence it had issued. We called it the "River of Silence:" for there seemed to be a hushing influence in its flow. No murmur arose from its bed, and so gently it wandered along, that the pearly pebbles upon which we loved to gaze, far down within its bosom, stirred not at all, but lay in a motionless content, each in its own old station, shining on gloriously forever.

Las palabras en cursivas constituyen términos o motivos retóricos (es decir, ecos numinosos) que he explorado a lo largo de este ensayo. Es cierto que el marco narrativo difiere de manera importante de los otros relatos, pero sin duda existe un hilo conector. Y Eleonora, por supuesto, es un nombre que resuena en "The Raven" a través de las reverberaciones del nombre de Lenore.

Así como algunos han argumentado que "Shadow" es una suerte de antecedente de "The Masque of the Red Death", ${ }^{8}$ en un sentido "Silence-A Fable" da pie a "Eleonora", concebido en 1841, más de diez años después de "Siope". Pero las referencias son también cruzadas: La efigie de la Peste en 
"The Masque", al igual que la Sombra en la parábola, carece de forma tangible, pero a diferencia de ésta no emite sonido alguno, sino que actúa inmersa en un silencio absoluto, como también sucede con la blanca figura en Pym. Además, los siete griegos recluidos en "Shadow" hacen un eco velado de las siete habitaciones en el palacio de Prince Prospero y de las siete candelas blancas en "The Pit and the Pendulum". El eco introducido por las campanadas del reloj en "The Masque" es reforzado con el uso repetido de la conjunción "and" (particularmente en el último párrafo), como también sucede a lo largo de "Silence-A Fable" y en "The Pit and the Pendulum"; ello produce la hipnosis fónica que, mediante el sonido -ore, sirve de guía a "The Raven". El sustantivo "dim" en la cita de "Eleonora" aparecía en la primera versión del soneto, como he mencionado antes.

También se puede ofrecer una óptica distinta (la poética del silencio) para leer "The Man of the Crowd" (1840), un relato que sistemáticamente se ha estudiado en función de la construcción de la modernidad y la figura del flâneur. Allí, el narrador descubre a un personaje intrigante y piensa: "How wild a story [...] is written within that bosom!" (§13; mi énfasis); hacia el final del relato, el narrador se da por vencido: sabe que no podrá aprender nada de ese rostro y de la conducta incierta del extraño hombre. Aquí se hace palpable la relación entre mundo y texto a la que se refiere Cantalupo (1995: 3), pero también resulta interesante advertir que el viejo al que sigue el narrador siempre se siente incómodo cuando se halla solo y en silencio, pero tranquilo y sosegado cuando está en medio de una multitud y de algarabía caótica. Se trata de un eco del hombre en toga de la "fábula del silencio", aunque inserto en un contexto menos alegórico. La ambientación de "Silence-A Fable" figura también en el poema "The Valley of Unrest", donde las palabras silent, red sun-light, restlessness, motionless, magic solitude, palpitate, lillies y nameless grave soportan el eje dramático del texto. Desde luego, los ecos de estas angustias no son producto de la casualidad, sino de una obsesión muy honda del autor. 


\section{Moralejas numinosas}

En los textos que he abordado, la presencia sobrehumana está lejos de ser reconfortante. Se trata de un numen estremecedor e inquietante; su hálito es más bien ominoso. Si pensamos en las formulaciones de Rudolph Otto, la presencia divina en la poética de Edgar Poe se acerca mucho más a la manifestación "numinosa" de la divinidad que a la "racional" (Otto 2001: 103). La primera se asocia a Dios como Yahvé (en quien prepondera el pavor religioso), mientras que Elohim (más patriarcal y familiar) corresponde con la segunda de estas manifestaciones. Pero al mismo tiempo, lo numinoso en Poe sugiere la presencia ominosa de la nada, una nada divina a la cual rehúyen los personajes: “La resistencia al ser propio del hombre es la nada, y la nada es Dios, lleva a Él; dejarse caer, hundirse en la nada es hundirse en el fondo secreto de lo divino" (Zambrano, 1993: 178). Este "fondo secreto" por necesidad tiene que producir estremecimiento, pues dimana de la inconmensurabilidad de lo numinoso. Desde esta perspectiva, las palabras de Harold Bloom (a quien nunca le ha simpatizado Poe), resultan pertinentes: "In Poe's myth (...) ethos is the daemon, and the daemon is our destiny" (Bloom, 2006: 6).

El aspecto del daimon para la conformación del numen, según lo elabora Otto, es lo que permite a Poe poder expresar una experiencia numinosa $\sin$ necesariamente tener que referirse a una divinidad en concreto. De acuerdo con Otto, el estado inferior del sentimiento numinoso está caracterizado por un pavor demoniaco, un pavor que emana de seres miríficos e inquietantes que deben distinguirse del "demonio" como un antidios (Otto, 2001: 100-101). Los daimon, en este sentido, son espíritus que anteceden a la configuración de los dioses propiamente dichos. El universo poético de Poe está sujeto, pues, no a dioses, sino a númenes y daimon.

Los dos "Silence", "Shadow", "The Masque of the Red Death" y otros textos comparten el hecho de que elaboran una escatología muy particular de la poética de Edgar Poe, una escatología que bien podría explicarse como una poética del refrain que recrea las estructuras dialécticas del epitafio, que invoca al espectral enviado de la muerte y que emula la majestuosidad silente de voces incorpóreas (Fried 1986: 629). El efecto de la iteración parece tener el objetivo de producir una suerte de hipnosis fónica 
que obliga a cruzar el umbral entre lo mundano y lo numinoso. Para ello, es al mismo tiempo menester que aparezca un ángel exterminador, ya sea bajo la apariencia de una sombra, de una muerte roja o del silencio; un ángel exterminador cuyo nombre es No more, como revela el soneto "Silence". Lo angustiante es que no podemos anticipar su llegada; cuando mucho podemos vislumbrar los "umbríos sonidos" que se mencionan en "Al Aaraaf". Ya es muy tarde para retroceder cuando advertimos que estamos inmersos en la "eterna voz de Dios", el silencio que supone la muerte.

Poe solía escribir prosa y componer poesía bajo sus particulares concepciones cosmológicas y a veces casi apocalípticas. Cuando uno se dedica a leer de cerca textos como éstos, no queda sino reconocer el gran genio de Poe. Más allá de la etiqueta de creador de la narrativa detectivesca o gran exponente de la literatura de terror, Edgar Allan Poe era un escritor con un pensamiento complejo y que podía desarrollar interesantes teorías físicas y metafísicas. La culminación de estas inquietudes intelectuales es Eureka, el tratado sobre el mundo natural y espiritual que Poe catalogó como un largo poema en prosa. Asimismo, es sugestivo el hecho de que "SilenceA Fable", "Shadow-A Parable", "The Masque of the Red Death" y "Eleonora" se cuenten entre los relatos más cortos que Poe escribió. Me siento tentado a afirmar que, desde esta óptica, el significado de la poética de Edgar Poe no equivale exclusivamente a los hilos narrativos; es decir que los recursos discursivos - tanto en prosa como en poesía - fungen más como tácticas estilísticas que como producto literario. Al igual que con los estribillos y las resonancias verbales en otros textos, Poe buscaba ante todo crear un efecto muy concreto, una metodología en consonancia con sus postulados en "The Philosophy of Composition".

He querido destacar el hecho de que la retórica de Poe se basa fuertemente en la resonancia numinosa, una representación de la poética del silencio, la cual subyace a una parte considerable de su producción literaria. Esta poética del silencio está construida no sólo mediante los efectos hipnóticos de sonidos en algunas historias, sino también merced a la presencia intertextual recurrente en diferentes composiciones. En este sentido, bien valdría la pena ponderar hasta qué grado la "sombra y duda" que acosan al narrador en "Eleonora" (\$2), por ejemplo, siguen 
respondiendo a esta poética del silencio. Como ha señalado un crítico, después del marco onírico-narrativo de este cuento, "The remainder of 'Eleonora', recounting the tale of successive love for Eleonora and Ermengarde, is related wholly in the past tense except for two brief statements, one declining to record the penalty assigned to breaking the vow and the other a repetition of the 'shadow' over his recollections of the 'second era' of his life" (Robinson, 1976: 44; mi énfasis). La conjunción del acto reiterativo y la presencia de una sombra remiten una vez más al ámbito del epitafio y de la resonancia numinosa.

Si se realiza una lectura cruzada de los textos que he discutido, es posible concluir que la Sombra es el aspecto terrible del Silencio, a su vez forma impávida e indiferente de la Muerte. Ello parece sobre todo cierto en "Shadow" y "Silence, a Sonnet". Pero en "Silence-A Fable" sucede algo distinto; como algunos apuntan, "Silence" intenta traspasar las barreras de la mortalidad para poder vislumbrar lo que yace del otro lado (Carlson, 1996: 150), pero, desde luego, es imposible contemplar al numen sin sucumbir. A semejanza de Job en los primeros capítulos, los personajes de Poe se enfrentan a menudo con el muro del silencio, un silencio que proviene no del mundo terrenal, sino del plano divino. Dicho silencio produce una sensación de desconsuelo que, las más de las veces, no tiene solución-a no ser la muerte. La tribulación de Job al menos le permitió lograr un contacto directo con su dios, si bien la declaración de Yahvé no responde a las inquisiciones de Job. Sin embargo, en esas últimas palabras dirigidas a Job desde el torbellino, esa gran oda a la creación (Job 38-41), se revela sin lugar a dudas su naturaleza de mysterium tremendum, cuya energía impone todo el peso de su majestas sobre la sufriente criatura.

Habría que pensar en qué sentido "Silence" y "Shadow" responden a, o pueden fungir como una re-presentación, no sólo del pasaje de Zacarías y el arcángel Gabriel en Lucas al que aludí páginas arriba, sino incluso de las palabras de Elifaz a Job, pero también de la respuesta grandilocuente de Yahvé a Job. En su visión, Elifaz, ante la percepción del terrible espectro, queda en silencio. A su vez, el gran poema de Yahvé sume a Job en el silencio. Por su parte, en la fábula de Poe el silencio impuesto conmociona: primero espanta al hombre de toga a través de la maldición del silencio; después al lector, merced a la inquietante y muda mirada del lince. 
Curiosamente, el narrador de "Silence" es capaz de recontar el relato que le ha hecho el Demonio, pero, una vez que éste ha terminado de hablar, es incapaz de reír o hablar. Su silencio es signo de su inferioridad y de su pasmo.

Como he señalado, el sonido que mengua en silencio es análogo a la sombra, una especie de eco visual. Los ecos de las súplicas de Job encontraron oídos que al final produjeron una respuesta que, aunque parcial, apaciguó la desolación del humilde, humillado y también indignado servidor de Dios. En contraparte, los cantos frenéticos en "Shadow" —antes que perderse en ecos de una manera armónica y natural- parecen quebrantar la armonía de la música de las esferas y producir una "melodía discordante" (Lubbers 1967: 378) que invoca a la Muerte. Esta desarmonía, esta falta de afinación cósmica, está presagiada en el inicio del relato mediante la descripción de los orbes (Shadow §1). Podríamos hablar de un insistente eco que perdura a través de la parábola entera. Y todo eco eventualmente se disuelve en el silencio. A final de cuentas, "El orden cósmico (...) necesita del silencio: dolor, sufrimiento y muerte" (Cohen,1996: 81). Así, Oinos canta, hace ruido, pero el silencio se impone, y el silencio supone la extinción. Hay que recordar también la insistencia que "SilenceA Fable" pone en el hecho de que la lengua va menguando, otra metáfora del eco que se debilita y desaparece.

La sombra de Poe opera en el mismo nivel que las palabras que Yahvé dirige a Job: no proveen de consuelo, sino que, por el contrario, revelan de modo apabullante las insondables fuerzas de la vida y de la muerte. De hecho, en Poe ni el silencio ni la sombra suelen estar asociados con el sosiego. Los recursos del silencio y la sombra atestiguan una profunda fobia a la nada, al no-ser. Y es que la nada

se parece a lo posible, a la sombra y al silencio (...) No es la misma, no tiene entidad, pero es activa, sombra de la vida también. Una de sus funciones es reducir: reduce a polvo (...) Por eso es la gran amenaza del hombre en cuanto proyecta su ser (Zambrano, 1993: 181).

En la "parábola", la Sombra desvela el alma de todos los recién fallecidos, al mismo tiempo que reclama nuevas almas. En la "fábula", el 
silencio infunde un terror absoluto, una turbación imposible de sobrellevar. En ambos casos, el numen de Poe deja entrever su semblante, aunque éste debe permanecer siempre oscuro, velado, en virtud de su carácter inefable. Al final, una descripción de la realidad numinosa y del último estadio de la vida terrenal ha de quedarse sin palabras, así como el desvanecimiento de las canciones griegas prefiguran el fallecimiento de Oinos.

Estamos ante una presencia divina que no es en absoluto luminosa, sino numinosa por completo. La inefabilidad de lo numinoso se traduce en el silencio de Poe y también en la imagen de la sombra, manifestación parcial de toda forma. Sin embargo, existe un hilo conductor a través de la obra de Poe: el eco. Esta resonancia asienta las bases de una poética del silencio, una poética que apela a la hipnosis simbólica de sonidos y motivos alegóricos. El lector, junto con los personajes de la poética de Poe, queda sumido en el temor y la inexorabilidad de la muerte. El terror religioso en la obra de Poe articula una compleja red textual que ora grita, ora calla. Ante el silencio, ante este silencio, sentimos una perplejidad profunda, esa mirada de lince, fija en los ojos del Demonio. 


\section{REFERENCIAS}

BACHELARD, Gaston (1942). El agua y los sueños. (trad. Ida Vitale). México: FCE.

BloOM, Harold (ed.) (2006): Bloom's Modern Critical Views: Edgar Allan Poe. NY: Chelsea House.

BROWN, Arthur A. (1994): "Literature and the Impossibility of Death: Poe's 'Berenice'”. En Nineteenth Century Literature. Núm.50: 4), pp. 448-463.

CANTAlupo, Barbara (1995): “The Lynx in Poe's 'Silence'”. En Poe Studies/Dark Romanticism. Núm. 28, 1-2 (June-Dec.), pp. 1-4.

CAPUTI, Anthony (1953): “The Refrain in Poe's Poetry". En American Literature, Núm. 25, 2 (May), pp. 169-78.

CARLSON, Eric W. (ed.) (1996): A Companion to Poe Studies. USA: Greenwood Press.

COHEN, Esther (1996): "El silencio de Dios". En Religión y sufrimiento. (comp. Isabel Cabrera y Elia Nathan) México: FFyL-UNAM, pp.7781.

FRIED, Debra (1986): “Repetition, Refrain, and Epitaph”. En ELH. Núm. 53, 3, pp. 615-32.

Halliburton, David (1973): Edgar Allan Poe. A Phenomenological View. New Jersey: Princeton University Press.

HARTMAN, Gerhard (1979): "Space and Symbol in the Tales of Edgar Allan Poe". En Poe Studies XII, Núm. 1, pp. 1-14. 
HAYES, Kevin J. (ed.) (2002). The Cambridge Companion to Edgar Allan Poe. UK: Cambridge University Press.

HooD, Thomas: The Poetical Works of Thomas Hood. Project Gutenberg: http:/ / www.gutenberg.org/etext/15652

INGEBRETSEN, Edward J (1996): Maps of Heaven, Maps of Hell. Religious Terror as Memory From the Puritans to Stephen King. NY/London: M.E. Sharpe.

LubBERS, Klaus (1967): “Poe's 'The Conqueror Worm'”. En American Literature. Núm. 39, 3 (Nov.), pp. 373-79.

MAввOTT, Thomas Ollive (ed.) (1969): The Collected Works of Edgar Allan Poe. Oxford University Press: London/NY.

Отто, Rudolph (1963): Lo santo. La racional y lo irracional en la idea de Dios. (trad.Fernando Vela). Madrid: Alianza.

POE, Edgar Allan (1998): Tales of Mystery and Imagination. (ed. Graham Clarke). London/Vermont: Everyman.

—_- (Poe Society) The Edgar Allan Poe Society of Baltimore: http:// www.eapoe.org/index.htm

RoBinsON, Arthur (1976): "Cosmic Vision in Poe's 'Eleonora'". En Poe Studies IX. Núm. 2 (June), pp. 44-46.

SovA, Dawn B (2001): Critical Companion to Edgar Allan Poe. A Literary Reference to His Life and Work. NY: Facts on Life.

WiLliams, Michael (1985): "Poe's 'Shadow—A Fable' and the Problem of Language". En American Literature. Núm. 57, 4 (Dec), pp. 622-32. 
POLIGRAFÍAS. REVISTA DE TEORÍA LITERARIA Y LITERATURA COMPARADA.NÚMERO 2. OTOÑO 2012

ZAMBRANO, María (1973): El hombre y lo divino. México: FCE. 